\title{
ISOLATION AND CHARACTERIZATION OF THE BIOLOGICALLY ACTIVE PREPARATION “GAMMA-PLANT" FROM THE GERMS OF Solanum tuberosum
}

\author{
L. A. Chekanovskaya ${ }^{1}$ and A. V. Generalov ${ }^{2}$
}

Translated from Khimiko-Farmatsevticheskii Zhurnal, Vol. 34, No. 3, pp. 51 - 56, March, 2000.

Original article submitted December 23, 1999.

Polysaccharides and mixed carbohydrate-containing polymers, glycolipids, glycoproteins, and glycopeptides, occur widely in biological systems, from plants and the simplest bacteria to higher animals. These substances are characterized by a very large variety of biological properties and structures, including compounds such as glycoproteins entering into the composition of cell membranes [1,2], lectins $[3-6]$, enzymes $[7,8]$, polysaccharides possessing antiviral [9] and antitumor activity [10], etc. In resent years, much effort is spent in the search for substances capable of modulating the biological response of the organism, in particular, reactions related to the recovery, correction, and enhancement or suppression of immune system functions. This direction of research is especially important from the standpoint of treating disorders of the immune system in the case of malignant tumors, irradiation-induced diseases, AIDS, etc.

A new preparation, called "gamma-plant" $(\gamma-\mathrm{Pl})$, belongs to the group of substances that can fill this immunobiological gap. At present $\gamma-\mathrm{Pl}$ is registered in the Russian Federation as an antiiflammatory drug (Registration Certificate No. 99/47/12). It was demonstrated that $\gamma$-Pl has an antiiflammatory effect in patients with reactive and rheumatoid arthritis. We have attempted to determine the active principle of $\gamma-\mathrm{Pl}$ based on the adjuvant properties of this substance. Below we report on the isolation and HPLC purification of a carbohydrate fraction from an aqueous extract of the germs of Solanum tuberosum potato, which constitutes the base of $\gamma-\mathrm{Pl}$ and which exhibits adjuvant activity. Previously we have demonstrated that $\gamma-\mathrm{Pl}$ exhibits pronounced antiviral activity $[11,12]$ and possesses immunomodulant properties [13], representing a powerful nontoxic interferon inductor [14].

\footnotetext{
${ }^{1}$ Institute of Molecular Genetics, Russian Academy of Sciences, Moscow, Russia.

2 First Moscow Isolation Hospital, Moscow, Russia.
}

\section{EXPERIMENTAL PART}

Potato tubers were kept for $3-4$ weeks at $37^{\circ} \mathrm{C}$ in a dark room with a humid atmosphere, after which the germs were collected, washed with tap water, and dried in air.

The chromatographic media and samples were prepared using solvents and reagents of analytical purity grade. Water was purified using a Milli-Q system (Millipore, Bedford, USA).

Pure dry potato germs were comminuted in an electric homogenizer and the final homogenate was poured into boiling distilled water in a $1: 1(\mathrm{v} / \mathrm{v})$ ratio under permanent stirring conditions and allowed to stand for $12 \mathrm{~h}$ at $4^{\circ} \mathrm{C}$. Then the cell debris was removed by squeezing, and the aqueous extract was purified by centrifuging at $4000 \mathrm{~g}$ for $20 \mathrm{~min}$.

To the resulting supernatant, cooled to $0-2^{\circ} \mathrm{C}$, was slowly added cold $\left(-10^{\circ} \mathrm{C}\right)$ acetone to a final concentration of $50 \%(\mathrm{v} / \mathrm{v})$. The mud was removed by 20 -min centrifuging at $4000 \mathrm{~g}$. Then the acetone content was increased to $70 \%$ and the mixture was centrifuged again to obtain a deposit containing the main fraction of the target substance.

The deposit was dissolved in water and precipitated with acetone as described above, this procedure being doubly repeated. The fraction precipitated in the interval of acetone concentrations from 50 to $70 \%$ was dissolved in water, dialyzed against distilled water at $4^{\circ} \mathrm{C}$, and freeze-dried (see Scheme 1).

The gel filtration was performed on a $1 \times 100 \mathrm{~cm}$ Ultrogel AcA44 column (LKB, Sweden) using a buffer solution comprising a mixture of 6 mmole $\mathrm{Na}_{2} \mathrm{HPO}_{4}$ and 4 mmole of citric acid monohydrate $\left(\mathrm{C}_{6} \mathrm{H}_{8} \mathrm{O}_{7} \cdot \mathrm{H}_{2} \mathrm{O}, \mathrm{pH} 6.6\right)$. The acetone fraction (AF) isolated as described above was dissolved in the same buffer.

The carbohydrate-containing fraction obtained upon gel filtration was applied onto a $1.7 \times 14 \mathrm{~cm}$ DEAE-52 cellulose 
Solanum tuberosum germs

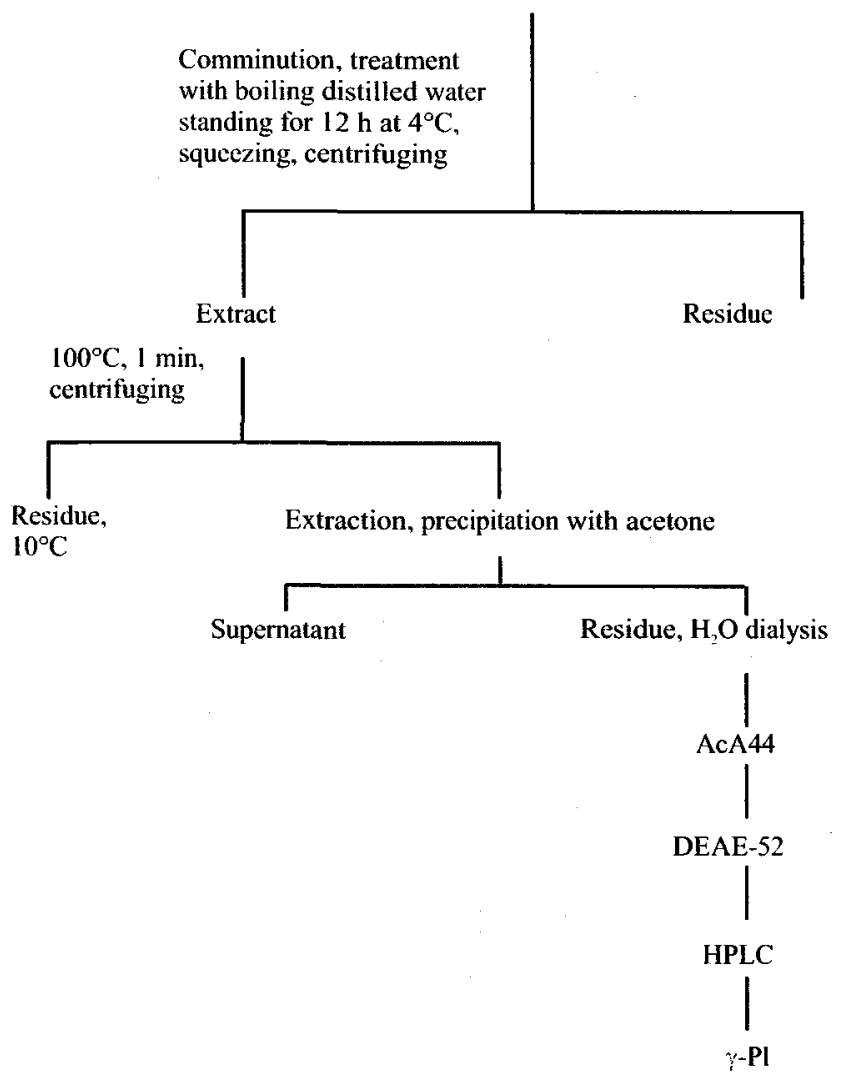

Scheme 1. Scheme of $\gamma-\mathrm{Pl}$ isolation from the germs of Solanum tuberosum.

column (Whatman, USA) preliminarily buffered with a mixture of 6 mmole $\mathrm{Na}_{2} \mathrm{HPO}_{4}$ and 4 mmole of citric acid monohydrate $\left(\mathrm{C}_{6} \mathrm{H}_{8} \mathrm{O}_{7} \cdot \mathrm{H}_{2} \mathrm{O}\right.$, pH 6.6). The sample was eluted with a linear gradient of $0.1-1.0 \mathrm{M} \mathrm{KCl}$ in a mixture of $10 \mathrm{mM}$ citric acid monohydrate $\left(\mathrm{C}_{6} \mathrm{H}_{8} \mathrm{O}_{7} \cdot \mathrm{H}_{2} \mathrm{O}, \mathrm{pH} 5\right)$ and $20 \mathrm{mM} \mathrm{NaOH}(\mathrm{pH} \mathrm{5})$. The fractions were concentrated and dialyzed by ultrafiltration in a Minitan cell (Millipore).

The final isolation of gamma-plant was performed by HPLC using a system including a Jasco Model PU-880 chromatographic pump (Jasco, Tokyo, Japan), a microprocessor-controlled UV - VIS detector (Jasco Model 870 UV), and a TSKG $6000 \mathrm{PW}(30 \mathrm{~cm} \times 7.5 \mathrm{~mm})$ column. The samples were introduced with a Rheodyne model 7120 injector (Rheodyne, Cotati, USA) with a working loop volume of $100 \mu 1$. The column was preliminarily washed with a mixture of $50 \mathrm{mmole} \mathrm{Na}_{2} \mathrm{HPO}_{4}$ and 50 mmole $\mathrm{NaH}_{2} \mathrm{PO}_{4}$ $(\mathrm{pH} \mathrm{6.8)}+0.1 \mathrm{M} \mathrm{NaCl}$ and eluted at the ambient temperature with the same buffer at a rate of $1 \mathrm{ml} / \mathrm{min}$. The detector was tuned to $220 \mathrm{~nm}$. The fraction obtained by HPLC is referred to as $\gamma-\mathrm{Pl}$.

Electrophoresis in a $7.5 \%$ poly(acrylamide) (PAA) gel containing $2.5 \%$ bisacrylamide and $1 \%$ sodium dodecylsulfate was performed according to Laemmli [15].
The samples of $\gamma$-Pl obtained as described above were introduced into holes of the same PAA gel under identical conditions. Upon electrophoresis, the gel block was cut into vertical fragments. The protein bands were detected by staining the gel segments in a solution containing $50 \%$ metanol, $10 \%$ acetic acid and $0.125 \%$ Coomassie Blue R-250 [16]. The gel segments were discolored by keeping for $72 \mathrm{~h}$ in a solution containing $5 \%$ of methanol and $7 \%$ of acetic acid. The markers used for estimating the molecular weight included bovine serum albumin $(67 \mathrm{kD})$, chicken egg ovalbumin (45 kD), glyceraldehyde-3-phosphate dehydrogenase from rabbit muscle $(36 \mathrm{kD})$, and trypsinogen from bovine pancreas $(24 \mathrm{kD})$. The presence of carbohydrate in the gel was detected by the Schiff method [17] or by staining the carbohydrate-containing fraction of glycoproteins with lectins labeled with fluorescent dyes. The specific sugar residues were determined using a fluorescein isothiocyanate - concanavalin A (Con A - FITC) conjugate (Serva, Germany) [18]. Carbohydrates were oxidized by $0,02 \%$ sodium periodate at a neutral $\mathrm{pH}$, the process being conducted for $2 \mathrm{~h}$ at $0^{\circ} \mathrm{C}$ in the dark. Then the gel was stained with fuchsin according to Fairbanks [19].

The carbohydrate fraction was stained with Con A - FITC after washing the gels in four portions of a $0.1 \mathrm{M}$ $\mathrm{NaCl}-0.05 \mathrm{M}$ TrisHCl buffer ( $\mathrm{pH} 7.0$ ) containing 1 mmole $\mathrm{CaCl}_{2}$ and $1 \mathrm{mmole} \mathrm{MnCl}_{2}$. Then the gels were kept for $12 \mathrm{~h}$ at room temperature in a $1 \mathrm{mg} / \mathrm{ml}$ Con A - FITC solution, followed by washing for two days in the above buffer. The fluorescent band in the gel was photographed under illumination with a long-wave UV radiation source. PAA gels with the bands stained for protein and carbohydrate were scanned on an Arcus II (AFGA, Germany) densitometer.

The amino acid analysis was performed on a Hitachi Amino Acid Analyzer (Japan) after hydrolysis with $6 \mathrm{M} \mathrm{HCl}$ in a nitrogen atmosphere at $110^{\circ} \mathrm{C}$ for $48 \mathrm{~h}$.

The $\gamma-\mathrm{Pl}$ carbohydrate fraction composition was determined by gas chromatography (GC) $[20,21]$. Monosaccharide derivatives in the form of polyol acetates were analyzed on an HP Model 5890A chromatograph (Hewlett-Packard, USA) with a flame-ionization detector, Ultra 2 capillary column (crosslinked 5\% $\mathrm{Ph} \quad \mathrm{Me}$ Silicon, $25 \mathrm{~m} \times 0.2 \mathrm{~mm} \times 0.33 \mathrm{~m}$ ), and an HP Model 3393A integrator in the regime of programmed temperature variation from 175 to $290^{\circ} \mathrm{C}$ at a rate of $10 \mathrm{~K} / \mathrm{min}$.

The $\gamma$-Pl samples $(3 \mathrm{mg}$ ) were hydrolyzed in $2 \mathrm{ml}$ of a $2 \mathrm{M}$ trifluoroacetic acid (TFA) containing inositol $(0.1 \mathrm{mg} / \mathrm{ml})$ as the internal standard. The process was performed for $1 \mathrm{~h}$ at $121^{\circ} \mathrm{C}$ in a sealed ampule, after which TFA was removed with $2 \mathrm{ml}$ of isopropanol or ethanol on a rotor evaporator at $40^{\circ} \mathrm{C}$. The residue was mixed with $3-4 \mathrm{ml}$ of a $1 \mathrm{M}$ aqueous ammonia solution containing sodium borohydride $(10 \mathrm{mg} / \mathrm{ml})$ and kept for $1 \mathrm{~h}$ at $40^{\circ} \mathrm{C}$, after which the excess sodium borohydride was converted into boric acid by adding $1 \mathrm{ml}$ of acetic acid. To this mixture were added $2 \mathrm{ml}$ of a methanol - acetic acid solution $(9: 1, \mathrm{v} / \mathrm{v})$, 
and the mixture was evaporated to dryness at $40^{\circ} \mathrm{C}$; then $2 \mathrm{ml}$ of methanol was added and the mixture was evaporated again. The residue was mixed with $1 \mathrm{ml}$ of pyridine and $1 \mathrm{ml}$ of acetic anhydride and the mixture was treated for $1 \mathrm{~h}$ at $100^{\circ} \mathrm{C}$. Upon cooling, $1 \mathrm{ml}$ of toluene was added and the mixture was evaporated to dryness. The residue was mixed with $2-3 \mathrm{ml}$ of water and the acetates were extracted with chloroform. The extracts were analyzed by GC, together with standard samples containing rhamnose, glucose, arabinose, etc.

The total protein content was determined by the Lowry method using bovine serum albumin as the standard [22]. The carbohydrate-containing fractions were identified by the Dubois method [23]. Uronic acid and amino sugars were determined using the 3,5-dimethylphenyl test [24] and the Morgan - Elson method.

The hydrolysis of $\gamma-\mathrm{Pl}$ was performed by lysozyme from chicken egg yoke (Boehringer Mannheim, Germany) and trypsin from bovine pancreas (Serva, Germany). A standard reaction medium for lysozyme was $100 \mathrm{mM}$ EDTA in $25 \mathrm{mM}$ TrisHCl ( $\mathrm{pH} 8.0$ ) and that for trypsin, $20 \mathrm{mM} \mathrm{CaCl}_{2}$ in $0.05 \mathrm{M} \mathrm{Na}_{2} \mathrm{~B}_{4} \mathrm{O}_{7} \cdot \mathrm{H}_{2} \mathrm{O} / 0.05 \mathrm{M} \mathrm{K}_{2} \mathrm{HPO}_{4}(\mathrm{pH} \mathrm{8.4)}$. The hydrolytic cleavage was effected at a $\gamma-\mathrm{Pl}$ to enzyme ratio of $100: 1$. The reaction mixtures with lysozyme and trypsin were incubated at $37^{\circ} \mathrm{C}$ for $30 \mathrm{~min}$ and $5 \mathrm{~h}$, respectively. The reactions were stopped by heating the reaction mixture for $30 \mathrm{~min}$ at $60^{\circ} \mathrm{C}$.

The biological experiments were performed on $(\mathrm{CBA} \times \mathrm{C} 57 \mathrm{BL}) \mathrm{F}_{1}$ white mice obtained from the "Stolbovaya" nursery of the Academy of Medical Sciences.

The adjuvant activity of $\gamma$-P1 was evaluated in vivo on the model of antibody genesis in response to suboptimal doses of heterologous erythrocytes. The mice were intraperitoneally immunized with $2 \times 10^{6}$ goat erythrocytes (GE) and the test animals simultaneously received $\gamma-\mathrm{Pl}$ at a dose of $1-100 \mu \mathrm{g}$ per mice in a volume of $0.2 \mathrm{ml}$. Prior to the immunization, the GE from defibrinated blood were triply washed with a 50-fold excess of Hanks' solution and then resuspended in the same medium. The level of immune response was determined by the amount of antibody-forming cells (AFC) determined in mice spleen by the Erne method $4-5$ days upon immunization [25]. In addition to the absolute AFC level, we have determined a relative characteristic - the stimulation coefficient $K_{\mathrm{s}}$ calculated as the ratio of the total AFC number in the test group to that in the control group.

The $\gamma$-Pl solutions were prepared by preliminarily dissolving $1 \mathrm{mg}$ of the substance in $1 \mathrm{ml}$ of Hanks' solution. The solutions were sterilized by filtration through single-use Millex (Millipore) filters with a pore size of $0.2 \mu \mathrm{m}$. The $\gamma$-Pl solutions treated with enzymes were sterilized after the reaction ended and used for immunization.

The $\gamma$-Pl complexes were also studied on a microscopic level. For this purpose a droplet of an aqueous sample solution was placed onto a freshly cleaved mica surface. Then the liquid was allowed to evaporate and the residue was exam-

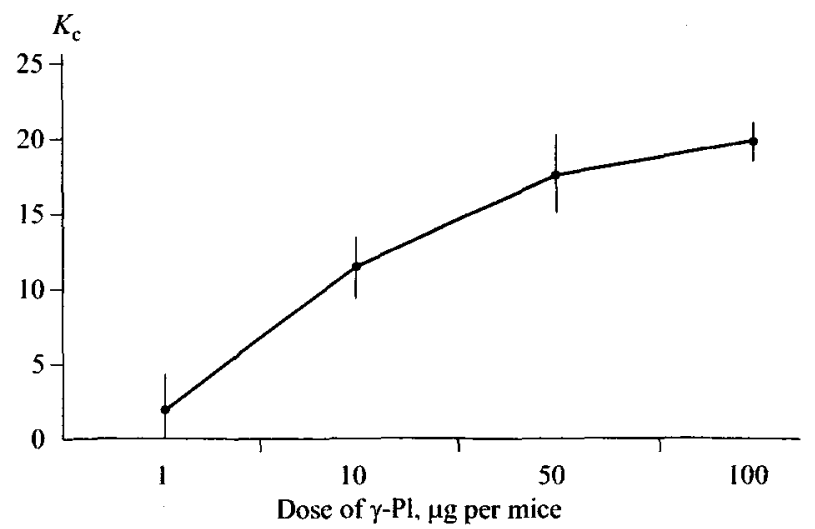

Fig. 1. Plot of the stimulation coefficient $K_{\mathrm{s}}$ versus $\gamma$-Pl dose demonstrating the effect of $\gamma-\mathrm{Pl}$ on antibody production in mice.

ined by scanning the mica surface in a NanoScope 3A atomic-force microscope (Visual Instruments, Santa Barbara, USA).

\section{RESULTS AND DISCUSSION}

Since the sample fractions were selected in all stages of $\gamma$-Pl isolation and purification based on the adjuvant activity of this substance, we will briefly characterize this property. Figure 1 presents a dose - effect plot showing the effect of $\gamma$-PI on the antibody production in the spleen of mice immunized with goat erythrocytes. As seen, the AFC production gradually increases to a maximum level attained at a $\gamma-\mathrm{Pl}$ dose of $50 \mu \mathrm{g}$ per mice.

All stages of the $\gamma$-Pl isolation are illustrated in the scheme. The main source of $\gamma-\mathrm{Pl}$ was the fraction precipitated in the interval of acetone concentrations from 50 to $70 \%$. Preliminary purification on an Ultrogel AcA44 allowed us to separate the fraction containing carbohydrates and proteins (determined by the Dubois and Lowry methods, respectively), reaching a sevenfold purification level (Table 1). The degree of purification was evaluated by the biological activity level. The next stage of purification after the gel filtration was provided by ion-exchange chromatography on DEAE-52 cellulose. The fraction eluted from the ion exchanger with $0.5 \mathrm{M} \mathrm{KCl}$ contained both carbohydrates and proteins and exhibited maximum adjuvant activity. On this fractionation stage, the degree of purity reaches 14 (Table 1). Table 1 indicates that a still higher degree of purification is provided by HPLC. Figure 2 shows the chromatographic profile of the $\gamma$-Pl fractions obtained by HPLC in comparison with the biological activity profile of these fractions. As seen, maximum adjuvant activity is observed for the peak corresponding to an elution time of $13 \mathrm{~min}$. This peak falls within the region of high molecular weights $\left(\sim 10^{6} \mathrm{D}\right)$.

We have studied the physicochemical characteristics and composition of $\gamma$-Pl obtained by HPLC (Table 2) and analyzed the adjuvant using the method of gel electrophoresis in 


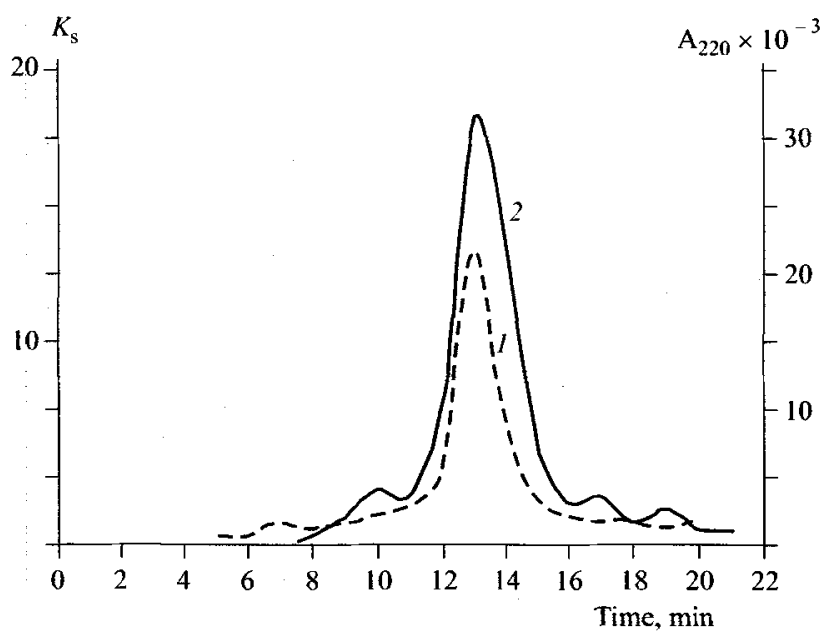

Fig. 2. Final $\gamma$-Pl purification stage by HPLC on a TSKG $6000 \mathrm{PW}$ column: $I$ ) adjuvant activity (stimulation coefficient $K_{\mathrm{s}}$ ) profile; 2) elution profile (UV absorption detector, $\lambda=230 \mathrm{~nm}$ ).

combination with band staining by reagents specific to carbohydrates and proteins (Fig. 3). The electrophoresis pattern of the adjuvant reveals the main band corresponding to a substance with a molecular weight of about $70 \mathrm{kD}$. The results of our experiments demonstrate that this substance is effectively stained by Coomassie Blue, Schiff reagent, and Con A - FITC conjugate, which is evidence that the $\gamma$-PI consists of two fragments - carbohydrate and protein. We suggest that the $70-\mathrm{kD}$ band represents a glycoprotein. Taking into account the well-known ability of Con A to bind specifically with mannose- and glucose-containing glycoproteins, this conclusion agrees with the monosaccharide composition of $\gamma$-Pl (Table 3) containing up to $70 \%$ of glucose. The monosaccharide composition of the carbohydrate fraction of $\gamma$-Pl includes the following components (mg): A, 3.7; XYL, 2.08; GAL, 6.84; MAN, 0.58; GLC, 70.70; uronic acids, 5.10; amino sugars, 1.0 .

We have treated $\gamma-\mathrm{Pl}$ with a number of enzymes having different specificities. Hydrolytic cleavage of $\gamma-\mathrm{Pl}$ with lysozyme (Table 4) and trypsin led to virtually complete loss of adjuvant activity. This is a remarkable fact, since lysozyme produces a strictly specific hydrolysis of the

TABLE 1. Isolation and Purification of Gamma-Plant from the Germs of Solanum tuberosum

\begin{tabular}{lcc}
\hline \multicolumn{1}{c}{ Stage } & Dry weight, $\mathrm{mg}$ & Degree of purification \\
\hline Nonpurified extract & 3500 & 1 \\
Acetone precipitation & 851 & 2 \\
Dialysis & 85.1 & 4 \\
Gel filtration (AcA44) & 12 & 7 \\
Ion-exchange chroma- & & \\
$\quad$ tography & 1.8 & 14 \\
HPLC & 0.13 & 28 \\
\hline
\end{tabular}

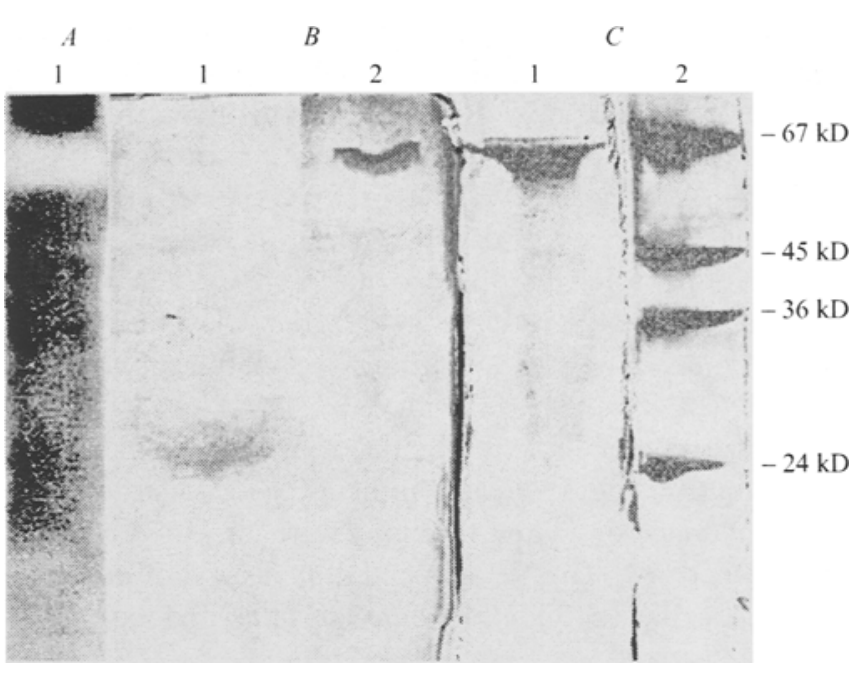

Fig. 3. The pattern of gel electrophoresis of $\gamma$-Pl showing bands in the segments of the same PAA gel stained with $A$ ) Con A - FITC; $B$ ) Schiff reagent and $C$ ) Coomassie Blue R-250: $(A 1, B 2, C 1) \gamma-\mathrm{Pl}$; $(B 1)$ immunoglobulin; $(C 2)$ weight markers bovine serum albumin $(67 \mathrm{kD})$, chicken egg ovalbumin (45 kD), glyceraldehyde-3-phosphate dehydrogenase from rabbit muscle $(36 \mathrm{kD})$, and trypsinogen from bovine pancreas $(24 \mathrm{kD})$.

1,4- $\beta$-glycoside bond between the residues of $\mathrm{N}$-acetyl-D-glucosamine in carbohydrate chains. Taking into account the small content of amino sugars (Table 3), we may suggest that $\gamma-\mathrm{Pl}$ possesses a rather unusual structure. Apparently, the biological activity (here, the adjuvant effect) manifestations of $\gamma$-Pl require the presence of both (protein and polysaccharide) fragments of the proposed glycoprotein.

Table 3 presents data on the amino acid composition of the protein fragment and the monosaccharide composition of the carbohydrate fragment of $\gamma$-Pl. As seen, the major fractions represent glutamic acid (Glu), serine (Ser), asparagic acid (Asp), and glycine (Gly). As is known from published

TABLE 2. Physicochemical Properties of Gamma-Plant from the Germs of Solanum tuberosum

\begin{tabular}{ll}
\hline \multicolumn{1}{c}{ Appcarance } & \multicolumn{1}{c}{ White powder } \\
\hline $\mathrm{pH}\left(1 \mathrm{mg} / \mathrm{ml}\right.$ deion. $\left.\mathrm{H}_{2} \mathrm{O}\right)$ & 5.22 \\
$\begin{array}{l}\text { Index of refraction }(2 \mathrm{mg} / \mathrm{ml} \\
\left.\quad \text { deion. } \mathrm{H}_{2} \mathrm{O}\right)\end{array}$ & $1.334 \pm 0.005$ \\
Elemental composition $(\%)$ & $\mathrm{C}, 40.26 ; \mathrm{H}, 5.94 ; \mathrm{N}, 1.84$ \\
UV spectrum in dist. $\mathrm{H}_{2} \mathrm{O}$ & $210(260-280 \mathrm{sh})$ \\
$\left(\lambda_{\max }, \mathrm{nm}\right)$ & \\
IR spectrum in $\mathrm{KBr}\left(\lambda_{\max }, \mathrm{cm}^{-1}\right)$ & $\begin{array}{l}3350,2920,1720,1620,1510, \\
1405,1378,1296,1145,1080, \\
1040,920,842,763\end{array}$ \\
Solubility & $\begin{array}{l}\text { Soluble in aqueous and salt media; } \\
\text { insoluble in ether, chloroform, ac- } \\
\text { etone, ethanol, DMSO }\end{array}$ \\
Composition, \% & Polysaccharide, $90 ;$ protein, 10 \\
\hline
\end{tabular}


TABLE 3. Amino Acid Composition of the Protein Fragment of Gamma-Plant*

\begin{tabular}{ccc}
\hline Amino acid residue & nmole & $\mathrm{ng} \times 10^{2}$ \\
\hline ASP & 102.9 & 136.66 \\
THR & 062.8 & 74.77 \\
SER & 142.7 & 149.86 \\
GLU & 186.0 & 273.46 \\
GLY & 162.2 & 121.69 \\
ALA & 101.1 & 89.99 \\
CYS & 18.4 & 44.32 \\
VAL & 73.7 & 86.45 \\
ILE & 31.8 & 41.83 \\
LEU & 72.9 & 95.66 \\
TYR & 22.4 & 40.63 \\
PHE & 28.9 & 47.80 \\
LYS & 51.3 & 75.00 \\
HIS & 15.8 & 24.53 \\
ARG & 30.2 & 52.62 \\
\hline
\end{tabular}

* Sample weight $100 \mathrm{mg}$.

TABLE 4. Content of GE-Antigen AFC Determined Four Days After $\gamma$-Pl Injection in Mice (Before and After Enzymatic Hydrolysis of $\gamma-\mathrm{Pl})$

\begin{tabular}{lc}
\hline \multicolumn{1}{c}{ Sample } & Number of anti-GE AFC \\
\hline $2 \times 10^{6} \mathrm{GE}$ & $45 \pm 3$ \\
$2 \times 10^{6} \mathrm{GE}+\gamma-\mathrm{Pl}$ & $1.2 \times 10^{3} \pm 105$ \\
$2 \times 10^{6} \mathrm{GE}+(\gamma-\mathrm{Pl}+$ lysozyme $)$ & $130 \pm 32$ \\
$2 \times 10^{6} \mathrm{GE}+$ lysozyme & $66 \pm 10$ \\
$2 \times 10^{6} \mathrm{GE}+(\gamma-\mathrm{Pl}+$ trypsin $)$ & $58 \pm 12$ \\
$2 \times 10^{6} \mathrm{GE}+$ trypsin & $83 \pm 18$ \\
\hline
\end{tabular}

data, glycoproteins are characterized by protein binding to oligosaccharides via $\mathrm{O}$ - and/or $\mathrm{N}$-glycoside bonds [26, 27]. Whether the proposed glycoprotein belongs to oligosaccharides featuring bonds of the $\mathrm{O}$ - or $\mathrm{N}$-glycoside type is still an open question. The protein fragment of $\gamma$-Pl contains a large amount of serine that may be involved in the formation of bonds of the Ser-O-Gly-can type. Note also the presence of a large amount of dicarboxylic (asparagic and glutamic) acids.

The high content of carboxy groups results in the $\gamma-\mathrm{Pl}$ molecule possessing a considerable negative charge. Moreover, $\gamma-\mathrm{Pl}$ molecules are capable of forming large molecular aggregates, each including $14-15$ subunits with a molecular weight of $70 \mathrm{kD}$. These aggregates were visualized with the aid of the atomic-force microscope (AFM) $[28,29]$. It was established that $\gamma$-P1 macromolecules adsorb well on a substrate (mica) surface from water without any additional preparation. Figure 4 shows the AFM image of $\gamma$-P1 molecules adsorbed on the mica surface, forming an almost homoge-

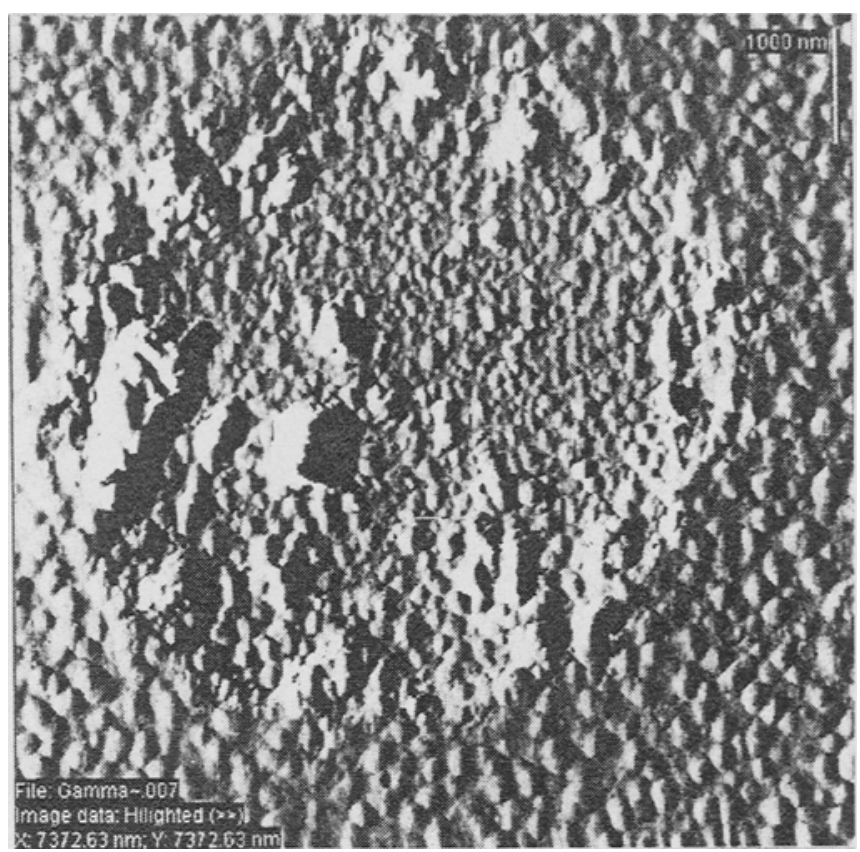

Fig. 4. AFM image of $\gamma$-PI complexes adsorbed from water on the mica surface.

neous coating. The coating exhibits a fine-grained structure with a lateral grain size of $200-400 \mathrm{~nm}$ and a height of $200-300 \mathrm{~nm}$. Probably, $\gamma$-Pl macromolecules adsorb on solids from aqueous solutions in the form of globular structures.Thus, we suggest that $\gamma-\mathrm{Pl}$, obtained by using a combination of methods with HPLC purification in the final stage, is a substance of glycoprotein nature. Whether $\gamma-\mathrm{Pl}$ is in fact a glycoprotein, is to be checked. Data on the biological properties of $\gamma$ - $\mathrm{Pl}$ are indicative of a significant immunostimulant activity of this agent. Beginning with a dose of $10 \mu \mathrm{g}$ per animal, $\gamma$-Pl injected into mice induced a $10-20$-fold increase in the amount of antibody-forming cells. This property allows $\gamma$-PI to be used as a nontoxic water-soluble immune adjuvant, in particular, for the production of hyperimmune sera for diagnostic and therapeutic purposes.

\section{ACKNOWLEDGMENTS}

Some parts of this work were performed with the participation of the leading scientific centers of Russia: Institute of Biophysics (Ministry of Public Health of the Russian Federation), Institute of Nutrition (Russian Academy of Medical Sciences), Zelinsky Institute of Organic Chemistry (Russian Academy of Sciences), and Moscow State University.

\section{REFERENCES}

1. T. Roemer, K. Madden, J. T. Chang, et al. Genes Development, 10, 777 - 793 (1996). 
2. J. L. Lopez-Ribot, M. Casanova, M. L. Gil, et al., Mycopathologia, 134, 13 - 20 (1996).

3. K. Kamemura, Y. Furuichi, H. Umekawa, et al., Biochim. Biophys. Acta-General Subjects, 1289, 87 - 94 (1996).

4. S. K. Nadimpalli and P. Kompella, Biochem. Mol. Biol. Int., 5, 1059 - 1066 (1996).

5. S. M. Moraes, B. S. Cavada, R. A. Moreira, et al., Brazilian J. Med. Biol. Res., 29, $977-985$ (1996).

6. S. Rosen, J. Bergstrom, K. A. Karlsson, et al., Eur. J. Biochem., 238, 830 - 837 (1996).

7. H. Oshi, S. Tsuda, Y. Watanabe, et al., Biosci. Biotech. Biochem., 60(7), $1087-1092$ (1996).

8. M. R. Terebiznik, A. M. R. Pilosof, S. Moreno, Food Biochem., 5(19), $341-354$ (1996).

9. P. Rouhier, M. Kopp, V. Begot, Phytochemictry, EN, 39(I), $57-62(1995)$.

10. T. Mizuno, T. Kinoshita, C. Zhuang, et al. Biosci. Biotech. Biochem., 59(4), 568 - 571 (1995).

11. L. A. Chekanovskaya, V. A. Meshik, and I. Yu. Orbachevskaya, Nauch. Issled. Zool. Paik. (Moscow), No. 5, 45 - 51 (1995).

12. V. A. Krikun, E. N. Kas'yan, and L. A. Chekanovskaya, $A$ Collection of Scientific Works of the Moscow State Academy of Veterinary and Biotechnology [in Russian], Moscow (1994), pp. $147-151$.

13. RF Patent No. $93,049,440$ (26.10.93); Byull. Izobret., No. 34 (1997)

14. L. A. Chekanovskaya, Vopr. Virusol., No. 3, 123 - 126 (1997).

15. U. K. Laemmli, Nature (London), 227, $680-685$ (1970).
16. K. Weber and M. Osborn, J. Biol. Chem., 244, 4406-4412 (1969).

17. R. M. Zacharius, T. E. Zell, J. H. Morrison, et al., Anal. Biochem., 30, 148 (1969).

18. M. Furlan, B. A. Perret, E. A. Beck, Anal. Biochem., 96, $208-214$ (1979).

19. G. Fairbanks, T. L Steck, and D. F. H. Wallach, Biochemistry, 10, 2606 (1971).

20. P. Albersheim, Methods Enzimol., 118, 3 - 40 (1987).

21. R. Whistler and J. Bemiller (eds.), Methods in Carbohydrate Chemistry, Vol. VI, Academic Press, New York (1972).

22. O. H. Lowry, N. J. Rosenbrough, A. L. Farã, et al., J. Biol. Chem., 193, 265 - 275 (1951).

23. M. Dubois, K. A. Gilles, J. K. Hamilton, et al., Anal. Chem., 28, $350-356$ (1956).

24. A. I. Usov, M. I. Bilan, N. G. Klochkova, Botanica Marina, 38, $43-51(1995)$.

25. R. J. Mitchell and R. W. Dutton, J. Exp. Med., 126, 423 - 432 (1967).

26. J. Montreuill, in: Comprehensive Biochemistry, Vol. 19B, Part 2, Elsevier, Amsterdam (1982), p. 1.

27. R. Kornfeld and S. Kornfeld, Annu. Rev. Biochem., 54, 631 (1985).

28. C. Bustamante, J. Vesenka, C. L. Tang, et al., Biochemistry, 31, $22-26$ (1992).

29. J. Vesenka, M. Guthod, C. L. Tang, et al., Ultramicroscopy, $42-44,1243-1249$ (1992). 